\title{
STRONG CONVERGENCE THEOREM FOR TWO ASYMPTOTICALLY QUASI-NONEXPANSIVE MAPPINGS WITH ERRORS IN BANACH SPACE
}

\author{
G. S. SALUJA
}

\begin{abstract}
In this paper, we study strong convergence of common fixed points of two asymptotically quasi-nonexpansive mappings and prove that if $K$ is a nonempty closed convex subset of a real Banach space $E$ and let $S, T: K \rightarrow K$ be two asymptotically quasi-nonexpansive mappings with sequences $\left\{u_{n}\right\},\left\{v_{n}\right\} \subset[0, \infty)$ such that $\sum_{n=1}^{\infty} u_{n}<\infty$ and $\sum_{n=1}^{\infty} v_{n}<\infty$, and $F=F(S) \cap F(T)=\{x \in K: S x=T x=x\} \neq \phi$. Suppose $\left\{x_{n}\right\}_{n=1}^{\infty}$ is generated iteratively by $x_{1} \in K$, and

$$
\begin{aligned}
x_{n+1} & =\left(1-\alpha_{n}\right) x_{n}+\alpha_{n} S^{n} y_{n}+l_{n} \\
y_{n} & =\left(1-\beta_{n}\right) x_{n}+\beta_{n} T^{n} x_{n}+m_{n}, \quad \forall n \in N
\end{aligned}
$$

where $\left\{l_{n}\right\}_{n=1}^{\infty},\left\{m_{n}\right\}_{n=1}^{\infty}$ are sequences in $K$ satisfying $\sum_{n=1}^{\infty}\left\|l_{n}\right\|<\infty, \sum_{n=1}^{\infty}\left\|m_{n}\right\|<\infty$ and $\left\{\alpha_{n}\right\},\left\{\beta_{n}\right\}$ are real sequences in $[0,1]$. It is proved that $\left\{x_{n}\right\}_{n=1}^{\infty}$ converges strongly to some common fixed point of $S$ and $T$. Our result is significant generalization of corresponding result of Ghosh and Debnath [3], Petryshyn and Williamson 7] and Qihou 8].
\end{abstract}

\section{Introduction and preliminaries}

Let $K$ be a nonempty subset of a real normed space $E$. Let $T$ be a self mapping of $K$. Then $T$ is said to be asymptotically nonexpansive with sequence $\left\{u_{n}\right\} \subset[0, \infty)$ if $\lim _{n \rightarrow \infty} u_{n}=0$ and

$$
\left\|T^{n} x-T^{n} y\right\| \leq\left(1+u_{n}\right)\|x-y\|
$$

for all $x, y \in K$ and $n \geq 1$; and is said to be asymptotically quasi-nonexpansive with sequence $\left\{u_{n}\right\} \subset[0, \infty)$ if $F(T)=\{x \in K: T x=x\} \neq \phi, \lim _{n \rightarrow \infty} u_{n}=0$ and

$$
\left\|T^{n} x-x^{*}\right\| \leq\left(1+u_{n}\right)\left\|x-x^{*}\right\|
$$

for all $x \in K, x^{*} \in F(T)$ and $n \geq 1$.

The mapping $T$ is called nonexpansive if

$$
\|T x-T y\| \leq\|x-y\|
$$

Received June 22, 2006; revised December 5, 2006.

2000 Mathematics Subject Classification. 47H10.

Key words and phrases. Asymptotically quasi-nonexpansive mapping, common fixed point, the modified Ishikawa iterative sequence with errors, Banach space. 
for all $x, y \in K$, and is called quasi-nonexpansive if $F(T) \neq \phi$ and

$$
\left\|T x-x^{*}\right\| \leq\left\|x-x^{*}\right\|
$$

for all $x \in K$ and $x^{*} \in F(T)$. It is therefore clear that a nonexpansive mapping with a nonempty fixed point set is quasi-nonexpansive and an asymptotically nonexpansive mapping with a nonempty fixed point set is asymptotically quasi-nonexpansive. The converse do not hold in general.

The class of asymptotically nonexpansive maps was introduced by Goebel and Kirk [1] as an important generalization of the class of nonexpansive maps. They established that if $K$ is a nonempty closed convex bounded subset of a uniformly convex Banach space $E$ and $T$ is an asymptotically nonexpansive self mapping of $K$, then $T$ has a fixed point. In 2], they extended this result to the broader class of uniformly $L$-Lipschitzian mappings with $L<\lambda$, where $\lambda$ is sufficiently near 1 .

In 1973, Petryshyn and Williamson 7], established a necessary and sufficient condition for a Mann iterative sequence to converge to a fixed point of a quasi-nonexpansive mapping. Subsequently, Ghosh and Debnath [3] extended Petryshyn and Williamson's results and established some necessary and sufficient conditions for an Ishikawa-type iterative sequence to converge to a fixed point of a quasi-nonexpansive mappings. Recently, in [8, 9], Qihou extended the results of Ghosh and Debnath to the more general class of quasi-nonexpansive mapping (i.e. asymptotically quasi-nonexpansive mappings).

The Ishikawa iteration process with errors $\left\{x_{n}\right\}_{n=1}^{\infty}$ (see, e.g., [5]) in $K$ defined as follows

$$
\begin{gathered}
x_{1} \in K, \\
x_{n+1}=\left(1-\alpha_{n}\right) x_{n}+\alpha_{n} T^{n} y_{n}+l_{n} \\
y_{n}=\left(1-\beta_{n}\right) x_{n}+\beta_{n} T^{n} x_{n}+m_{n}
\end{gathered}
$$

where $\left\{l_{n}\right\}_{n=1}^{\infty},\left\{m_{n}\right\}_{n=1}^{\infty}$ are sequences in $K$ satisfying $\sum_{n=1}^{\infty}\left\|l_{n}\right\|<\infty, \sum_{n=1}^{\infty}\left\|m_{n}\right\|<$ $\infty$ and $\left\{\alpha_{n}\right\}_{n=1}^{\infty}$ and $\left\{\beta_{n}\right\}_{n=1}^{\infty}$ are two real sequences in $[0,1]$ satisfying certain conditions.

It is clear that the Ishikawa iteration process with errors is a generalized case of the Ishikawa iteration process [4], while for all $n \in N$, setting $\beta_{n}=0$, it reduces to the Mann iteration process with errors which is a generalized case of the Mann iteration process 6].

Let $K$ be a nonempty subset of a real Banach space $X$ and $S, T: K \rightarrow K$ be two asymptotically quasi-nonexpansive mappings. Consider the following modified Ishikawa iteration process with errors $\left\{x_{n}\right\}_{n=1}^{\infty}$ defined as follows:

$$
\begin{gathered}
x_{1} \in K, \\
x_{n+1}=\left(1-\alpha_{n}\right) x_{n}+\alpha_{n} S^{n} y_{n}+l_{n} \\
y_{n}=\left(1-\beta_{n}\right) x_{n}+\beta_{n} T^{n} x_{n}+m_{n}
\end{gathered}
$$

where $\left\{l_{n}\right\}_{n=1}^{\infty},\left\{m_{n}\right\}_{n=1}^{\infty}$ are sequences in $K$ satisfying $\sum_{n=1}^{\infty}\left\|l_{n}\right\|<\infty, \sum_{n=1}^{\infty}\left\|m_{n}\right\|<$ $\infty$ and $\left\{\alpha_{n}\right\}_{n=1}^{\infty}$ and $\left\{\beta_{n}\right\}_{n=1}^{\infty}$ are two real sequences in $[0,1]$ satisfying certain conditions. 
It is clear that if we put $S=T$, then iterative sequences defined by (2) reduces to the sequences defined by (11).

In this paper, we establish a necessary and sufficient conditions for the convergence of the modified Ishikawa iterative sequence with errors involving two asymptotically quasi-nonexpansive mappings defined by (2) to a common fixed point of the mappings defined on a nonempty closed convex subset of a Banach space. Our result is significant generalization of Ghosh and Debnath [3], Petryshyn and Williamson [7] and Qihou 8].

We need the following Lemmas to prove our main result:

Lemma 1.0.1. Let $E$ be a real Banach space and $K$ a nonempty closed convex subset of $E$. Let $S, T: K \rightarrow K$ be two asymptotically quasi-nonexpansive mappings with sequences $\left\{u_{n}\right\},\left\{v_{n}\right\} \subset[0, \infty)$ such that $\sum_{n=1}^{\infty} u_{n}<\infty$ and $\sum_{n=1}^{\infty} v_{n}<\infty$ and $F=F(S) \cap F(T)=\{x \in K: S x=T x=x\} \neq \phi$. Let $\left\{\alpha_{n}\right\}$ and $\left\{\beta_{n}\right\}$ be sequences in $[0,1]$. Starting from arbitrary $x_{1} \in K$, define the sequence $\left\{x_{n}\right\}$ iteratively by

$$
\begin{aligned}
x_{n+1} & =\left(1-\alpha_{n}\right) x_{n}+\alpha_{n} S^{n} y_{n}+l_{n} \\
y_{n} & =\left(1-\beta_{n}\right) x_{n}+\beta_{n} T^{n} x_{n}+m_{n}, \quad \forall n \in N
\end{aligned}
$$

where $\left\{l_{n}\right\}_{n=1}^{\infty},\left\{m_{n}\right\}_{n=1}^{\infty}$ are sequences in $K$ satisfying $\sum_{n=1}^{\infty}\left\|l_{n}\right\|<\infty, \sum_{n=1}^{\infty}\left\|m_{n}\right\|<$ $\infty$. Then

(a) $\left\|x_{n+1}-x^{*}\right\| \leq\left(1+b_{n}\right)\left\|x_{n}-x^{*}\right\|+t_{n}$, for all $n \geq 1, x^{*} \in F=F(S) \cap F(T)$, where $b_{n}=u_{n}+v_{n}+u_{n} v_{n}$ with $\sum_{n=1}^{\infty} b_{n}<\infty$ and $t_{n}=\left(1+u_{n}\right)\left\|m_{n}\right\|+\left\|l_{n}\right\|$.

(b) There exists a constant $M>0$ such that

$$
\left\|x_{n+m}-x^{*}\right\| \leq M\left\|x_{n}-x^{*}\right\|+M \sum_{k=n}^{n+m-1} t_{k}
$$

for all $n, m \geq 1$ and $x^{*} \in F$.

Proof. (a) Let $x^{*} \in F$. Then we have from (A)

$$
\begin{aligned}
\left\|x_{n+1}-x^{*}\right\| & =\left\|\left(1-\alpha_{n}\right) x_{n}+\alpha_{n} S^{n} y_{n}+l_{n}-x^{*}\right\| \\
& =\left\|\left(1-\alpha_{n}\right)\left(x_{n}-x^{*}\right)+\alpha_{n}\left(S^{n} y_{n}-x^{*}\right)+l_{n}\right\| \\
& \leq\left(1-\alpha_{n}\right)\left\|x_{n}-x^{*}\right\|+\alpha_{n}\left\|S^{n} y_{n}-x^{*}\right\|+\left\|l_{n}\right\| \\
& \leq\left(1-\alpha_{n}\right)\left\|x_{n}-x^{*}\right\|+\alpha_{n}\left(1+u_{n}\right)\left\|y_{n}-x^{*}\right\|+\left\|l_{n}\right\|
\end{aligned}
$$

and

$$
\begin{aligned}
\left\|y_{n}-x^{*}\right\| & =\left\|\left(1-\beta_{n}\right) x_{n}+\beta_{n} T^{n} x_{n}+m_{n}-x^{*}\right\| \\
& =\left\|\left(1-\beta_{n}\right)\left(x_{n}-x^{*}\right)+\beta_{n}\left(T^{n} x_{n}-x^{*}\right)+m_{n}\right\| \\
& \leq\left(1-\beta_{n}\right)\left\|x_{n}-x^{*}\right\|+\beta_{n}\left\|T^{n} x_{n}-x^{*}\right\|+\left\|m_{n}\right\| \\
& \leq\left(1-\beta_{n}\right)\left\|x_{n}-x^{*}\right\|+\beta_{n}\left(1+v_{n}\right)\left\|x_{n}-x^{*}\right\|+\left\|m_{n}\right\| \\
& \leq\left[1-\beta_{n}+\beta_{n}\left(1+v_{n}\right)\right]\left\|x_{n}-x^{*}\right\|+\left\|m_{n}\right\| \\
& \leq\left(1+v_{n}\right)\left\|x_{n}-x^{*}\right\|+\left\|m_{n}\right\|
\end{aligned}
$$


from (3) and (41), we have

$$
\begin{aligned}
\left\|x_{n+1}-x^{*}\right\| & \leq\left(1-\alpha_{n}\right)\left\|x_{n}-x^{*}\right\|+\alpha_{n}\left(1+u_{n}\right)\left[\left(1+v_{n}\right)\left\|x_{n}-x^{*}\right\|+\left\|m_{n}\right\|\right]+\left\|l_{n}\right\| \\
& \leq\left[1-\alpha_{n}+\alpha_{n}\left(1+u_{n}\right)\left(1+v_{n}\right)\right]\left\|x_{n}-x^{*}\right\|+\alpha_{n}\left(1+u_{n}\right)\left\|m_{n}\right\|+\left\|l_{n}\right\| \\
& \leq\left[1+\alpha_{n}\left(u_{n}+v_{n}+u_{n} v_{n}\right)\right]\left\|x_{n}-x^{*}\right\|+\alpha_{n}\left(1+u_{n}\right)\left\|m_{n}\right\|+\left\|l_{n}\right\| \\
& \leq\left[1+u_{n}+v_{n}+u_{n} v_{n}\right]\left\|x_{n}-x^{*}\right\|+\left(1+u_{n}\right)\left\|m_{n}\right\|+\left\|l_{n}\right\| \\
& \leq\left(1+b_{n}\right)\left\|x_{n}-x^{*}\right\|+t_{n}
\end{aligned}
$$

where $b_{n}=u_{n}+v_{n}+u_{n} v_{n}$ with $\sum_{n=1}^{\infty} b_{n}<\infty$ and $t_{n}=\left(1+u_{n}\right)\left\|m_{n}\right\|+\left\|l_{n}\right\|$.

This completes the proof of (a).

(b) Since $1+x \leq e^{x}$ for all $x>0$. Then from (a) it can be obtained that

$$
\begin{aligned}
& \left\|x_{n+m}-x^{*}\right\| \leq\left(1+b_{n+m-1}\right)\left\|x_{n+m-1}-x^{*}\right\|+t_{n+m-1} \\
& \leq e^{b_{n+m-1}}\left\|x_{n+m-1}-x^{*}\right\|+t_{n+m-1} \\
& \leq e^{\left(b_{n+m-1}+b_{n+m-2}\right)}\left\|x_{n+m-2}-x^{*}\right\|+e^{b_{n+m-1}} t_{n+m-2}+t_{n+m-1} \\
& \leq e^{\left(b_{n+m-1}+b_{n+m-2}\right)}\left\|x_{n+m-2}-x^{*}\right\|+e^{b_{n+m-1}}\left(t_{n+m-1}+t_{n+m-2}\right) \\
& \leq \ldots \ldots \ldots \ldots \ldots \ldots \ldots \ldots \ldots \ldots \ldots \ldots \ldots \ldots \ldots \\
& \leq e^{\sum_{k=n}^{n+m-1} b_{k}}\left\|x_{n}-x^{*}\right\|+e^{\sum_{k=n}^{n+m-1} b_{k}} \sum_{k=n}^{n+m-1} t_{k} \\
& \leq M\left\|x_{n}-x^{*}\right\|+M \sum_{k=n}^{n+m-1} t_{k}, \quad \text { where } M=e^{\sum_{k=n}^{\infty} b_{k}}
\end{aligned}
$$

This completes the proof of (b).

Lemma 1.0.2.(9, Lemma 2]) Let $\left\{a_{n}\right\}_{n=1}^{\infty},\left\{\beta_{n}\right\}_{n=1}^{\infty}$ and $\left\{r_{n}\right\}_{n=1}^{\infty}$ be sequences of nonnegative real numbers satisfying

$$
a_{n+1} \leq\left(1+r_{n}\right) a_{n}+\beta_{n}, \quad \forall n \in N .
$$

If $\sum_{n=1}^{\infty} r_{n}<\infty, \sum_{n=1}^{\infty} \beta_{n}<\infty$. Then

(i) $\lim _{n \rightarrow \infty} a_{n}$ exists.

(ii) If $\liminf _{n \rightarrow \infty} a_{n}=0$, then $\lim _{n \rightarrow \infty} a_{n}=0$.

\section{Main result}

Theorem 2.0.3. Let $E$ be a real Banach space and $K$ a nonempty closed convex subset of $E$. Let $S, T: K \rightarrow K$ be to asymptotically quasi-nonexpansive mappings ( $S$ and $T$ need not be continuous) with sequences $\left\{u_{n}\right\},\left\{v_{n}\right\} \subset[0, \infty)$ such that $\sum_{n=1}^{\infty} u_{n}<\infty$ and $\sum_{n=1}^{\infty} v_{n}<\infty$, and $F=F(S) \cap F(T)=\{x \in K: S x=T x=x\} \neq \phi$. Let $\left\{\alpha_{n}\right\}$ and 
$\left\{\beta_{n}\right\}$ be sequences in $[0,1]$. From arbitrary $x_{1} \in K$, define the sequence $\left\{x_{n}\right\}$ iteratively by

$$
\begin{aligned}
x_{n+1} & =\left(1-\alpha_{n}\right) x_{n}+\alpha_{n} S^{n} y_{n}+l_{n} \\
y_{n} & =\left(1-\beta_{n}\right) x_{n}+\beta_{n} T^{n} x_{n}+m_{n}, \quad \forall n \in N
\end{aligned}
$$

where $\left\{l_{n}\right\}_{n=1}^{\infty},\left\{m_{n}\right\}_{n=1}^{\infty}$ are sequences in $K$ satisfying $\sum_{n=1}^{\infty}\left\|l_{n}\right\|<\infty, \sum_{n=1}^{\infty}\left\|m_{n}\right\|<$ $\infty$. Then $\left\{x_{n}\right\}$ converges strongly to some common fixed point of $S$ and $T$ if and only if $\liminf _{n \rightarrow \infty} d\left(x_{n}, F\right)=0$.

Proof. Suppose $\left\{x_{n}\right\}_{n=1}^{\infty}$ converges strongly to some common fixed point $z$ of $S$ and $T$. Then

$$
\liminf _{n \rightarrow \infty} d\left(x_{n}, F\right)=0
$$

Conversely, suppose

$$
\liminf _{n \rightarrow \infty} d\left(x_{n}, F\right)=0
$$

Then from Lemma 1.0.1, we have

$$
\left\|x_{n+1}-x^{*}\right\| \leq\left(1+b_{n}\right)\left\|x_{n}-x^{*}\right\|+t_{n}, \quad \forall n \in N, \quad \forall x^{*} \in F
$$

Since $\sum_{n=1}^{\infty} u_{n}<\infty, \sum_{n=1}^{\infty} v_{n}<\infty, \sum_{n=1}^{\infty}\left\|l_{n}\right\|<\infty, \sum_{n=1}^{\infty}\left\|m_{n}\right\|<\infty$, thus we know $\sum_{n=1}^{\infty} b_{n}<\infty$ and $\sum_{n=1}^{\infty} t_{n}<\infty$. So from (5), we obtain

$$
d\left(x_{n+1}, F\right) \leq\left(1+b_{n}\right) d\left(x_{n}, F\right)+t_{n},
$$

since $\liminf \operatorname{in}_{n \rightarrow \infty} d\left(x_{n}, F\right)=0$ and from Lemma 1.0.2, we have $\lim _{n \rightarrow \infty} d\left(x_{n}, F\right)=0$.

Next we will show that $\left\{x_{n}\right\}_{n=1}^{\infty}$ is a Cauchy sequence. For all $\varepsilon>0$, from Lemma 1.0.1, it can be known that there must exists a constant $M>0$, such that

$$
\left\|x_{n+m}-x^{*}\right\| \leq M\left\|x_{n}-x^{*}\right\|+M \sum_{k=n}^{n+m-1} t_{k}, \quad \forall x^{*} \in F, \quad \forall m, n \in N
$$

since $\lim _{n \rightarrow \infty} d\left(x_{n}, F\right)=0$ and $\sum_{k=n}^{\infty} t_{k}<\infty$, then there must exists a constant $N_{1}$, such that when $n \geq N_{1}$

$$
d\left(x_{n}, F\right)<\frac{\varepsilon_{1}}{3 M}, \quad \text { and } \quad \sum_{k=n}^{\infty} t_{k}<\frac{\varepsilon_{1}}{6 M} .
$$

So there must exists $w^{*} \in F$, such that

$$
d\left(x_{N_{1}}, w^{*}\right)=\left\|x_{N_{1}}-w^{*}\right\|<\frac{\varepsilon_{1}}{3 M} .
$$


From (6), it can be obtained that when $n \geq N_{1}$

$$
\begin{aligned}
\left\|x_{n+m}-x_{n}\right\| & \leq\left\|x_{n+m}-w^{*}\right\|+\left\|x_{n}-w^{*}\right\| \\
& \leq M\left\|x_{N_{1}}-w^{*}\right\|+M\left\|x_{N_{1}}-w^{*}\right\|+2 M \sum_{k=N_{1}}^{\infty} t_{k} \\
& <M \frac{\varepsilon_{1}}{3 M}+M \frac{\varepsilon_{1}}{3 M}+2 M \frac{\varepsilon_{1}}{6 M} \\
& <\varepsilon_{1}
\end{aligned}
$$

that is

$$
\left\|x_{n+m}-x_{n}\right\|<\varepsilon_{1} .
$$

This shows that $\left\{x_{n}\right\}_{n=1}^{\infty}$ is a Cauchy sequence and so is convergent, since $E$ is complete. Let $\lim _{n \rightarrow \infty} x_{n}=y^{*}$. Then $y^{*} \in K$. It remains to show that $y^{*} \in F$. Let $\varepsilon_{2}>0$ be given. Then there exists a natural number $N_{2}$ such that

$$
\left\|x_{n}-y^{*}\right\|<\frac{\varepsilon_{2}}{2 . \max \left\{2+u_{1}, 2+v_{1}\right\}}, \quad \forall n \geq N_{2} .
$$

Since $\lim _{n \rightarrow \infty} d\left(x_{n}, F\right)=0$, there must exists a natural number $N_{3} \geq N_{2}$ such that for all $n \geq N_{3}$, we have

$$
d\left(x_{n}, F\right)<\frac{\varepsilon_{2}}{3 . \max \left\{2+u_{1}, 2+v_{1}\right\}},
$$

and in particular we have

$$
d\left(x_{N_{3}}, F\right)<\frac{\varepsilon_{2}}{3 . \max \left\{2+u_{1}, 2+v_{1}\right\}} .
$$

Therefore, there exists $z^{*} \in F$ such that

$$
\left\|x_{N_{3}}-z^{*}\right\|<\frac{\varepsilon_{2}}{2 . \max \left\{2+u_{1}, 2+v_{1}\right\}} .
$$

Consequently, we have

$$
\begin{aligned}
\left\|S y^{*}-y^{*}\right\| & =\left\|S y^{*}-z^{*}+z^{*}-x_{N_{3}}+x_{N_{3}}-y^{*}\right\| \\
& \leq\left\|S y^{*}-z^{*}\right\|+\left\|z^{*}-x_{N_{3}}\right\|+\left\|x_{N_{3}}-y^{*}\right\| \\
& \leq\left(1+u_{1}\right)\left\|y^{*}-z^{*}\right\|+\left\|z^{*}-x_{N_{3}}\right\|+\left\|x_{N_{3}}-y^{*}\right\| \\
& \leq\left(1+u_{1}\right)\left\|y^{*}-x_{N_{3}}+x_{N_{3}}-z^{*}\right\|+\left\|z^{*}-x_{N_{3}}\right\|+\left\|x_{N_{3}}-y^{*}\right\| \\
& \leq\left(1+u_{1}\right)\left[\left\|y^{*}-x_{N_{3}}\right\|+\left\|x_{N_{3}}-z^{*}\right\|\right]+\left\|z^{*}-x_{N_{3}}\right\|+\left\|x_{N_{3}}-y^{*}\right\| \\
& \leq\left(2+u_{1}\right)\left\|y^{*}-x_{N_{3}}\right\|+\left(2+u_{1}\right)\left\|x_{N_{3}}-z^{*}\right\| \\
& <\left(2+u_{1}\right) \cdot \frac{\varepsilon_{2}}{2 \cdot \max \left\{2+u_{1}, 2+v_{1}\right\}}+\left(2+u_{1}\right) \cdot \frac{\varepsilon_{2}}{2 . \max \left\{2+u_{1}, 2+v_{1}\right\}} \\
& <\varepsilon_{2} .
\end{aligned}
$$

This implies that $y^{*} \in F(S)$. 
Similarly, we have

$$
\begin{aligned}
\left\|T y^{*}-y^{*}\right\| & =\left\|T y^{*}-z^{*}+z^{*}-x_{N_{3}}+x_{N_{3}}-y^{*}\right\| \\
& \leq\left\|T y^{*}-z^{*}\right\|+\left\|z^{*}-x_{N_{3}}\right\|+\left\|x_{N_{3}}-y^{*}\right\| \\
& \leq\left(1+v_{1}\right)\left\|y^{*}-z^{*}\right\|+\left\|z^{*}-x_{N_{3}}\right\|+\left\|x_{N_{3}}-y^{*}\right\| \\
& \leq\left(1+v_{1}\right)\left\|y^{*}-x_{N_{3}}+x_{N_{3}}-z^{*}\right\|+\left\|z^{*}-x_{N_{3}}\right\|+\left\|x_{N_{3}}-y^{*}\right\| \\
& \leq\left(1+v_{1}\right)\left[\left\|y^{*}-x_{N_{3}}\right\|+\left\|x_{N_{3}}-z^{*}\right\|\right]+\left\|z^{*}-x_{N_{3}}\right\|+\left\|x_{N_{3}}-y^{*}\right\| \\
& \leq\left(2+v_{1}\right)\left\|y^{*}-x_{N_{3}}\right\|+\left(2+v_{1}\right)\left\|x_{N_{3}}-z^{*}\right\| \\
& <\left(2+v_{1}\right) \cdot \frac{\varepsilon_{2}}{2 . \max \left\{2+u_{1}, 2+v_{1}\right\}}+\left(2+v_{1}\right) \cdot \frac{\varepsilon_{2}}{2 \cdot \max \left\{2+u_{1}, 2+v_{1}\right\}} \\
& <\varepsilon_{2} .
\end{aligned}
$$

This implies that $y^{*} \in F(T)$. Hence we conclude that $y^{*} \in F=F(S) \cap F(T)$, that is, $y^{*}$ is a common fixed point of $S$ and $T$. Thus $\left\{x_{n}\right\}_{n=1}^{\infty}$ converges strongly to some common fixed point of $S$ and $T$. This completes the proof.

Remark 1. If we put $l_{n}=m_{n}=0, \forall n \in N, S=T$ and $u_{n}=v_{n}$, then Theorem 1 of Qihou [8, p.2] is a corollary to the Theorem 2.0.3.

Remark 2. Theorem 2.0.3 contains as special cases of the main result of Qihou 8 , Theorem 1, p.2] together with [8, Corollaries 1 and 2], which are themselves extensions of the results of Ghosh and Debnath [3] Petryshyn and Williamson [7].

Remark 3. Theorem 2.0.3 remains true for the subclass of asymptotically nonexpansive mappings.

\section{References}

[1] K. Goebel and W. A. Kirk, A fixed point theorem for asymptotically nonexpansive mappings, Proc. Amer. Math. Soc. 35 (1972), 171-174.

[2] K. Goebel and W.A. Kirk, A fixed point theorem for transformations whose iterates have uniform Lipschitz constant, Studia Mathematica 47 (1973), 135-140.

[3] M. K. Ghosh and L. Debnath, Convergence of Ishikawa iterations of quasi-nonexpansive mappings, J. Math. Anal. Appl. 207 (1997), 96-103.

[4] S. Ishikawa, Fixed points by a new iteration method, Proc. Amer. Math. Soc. 44 (1974), 147-150.

[5] L.S. Liu, Ishikawa and Mann iterative process with errors for nonlinear strongly accretive mappings in Banach spaces, J. Math. Anal. Appl. 194 (1995), 114-125.

[6] W. R. Mann, Mean value methods in iteration, Proc. Amer. Math. Soc. 4 (1953), 506-510.

[7] W. V. Petryshyn and T. E. Williamson, Strong and weak convergence of the sequence of successive approximations for quasi-nonexpansive mappings, J. Math. Anal. Appl. 43 (1973), 459-497.

[8] L. Qihou, Iterative sequences for asymptotically quasi-nonexpansive mappings, J. Math. Anal. Appl. 259 (2001), 1-7. 
[9] L. Qihou, Iterative sequences for asymptotically quasi-nonexpansive mappings with error member, J. Math. Anal. Appl. 259 (2001), 18-24.

Department of Mathematics \& I.T., Govt. College of Science, Raipur (C.G.).

E-mail: saluja_1963@rediffmail.com 